\title{
Article \\ Comparison of Holmium:YAG and Thulium Fiber Lasers on the Risk of Laser Fiber Fracture
}

\author{
Audrey Uzan ${ }^{1,2}$, Paul Chiron ${ }^{1,2}$, Frédéric Panthier ${ }^{1,2}$, Mattieu Haddad ${ }^{1,2}$, Laurent Berthe ${ }^{3} \mathbb{D}$, Olivier Traxer ${ }^{1,2} \mathbb{D}$ \\ and Steeve Doizi ${ }^{1,2, *(D)}$ \\ 1 Sorbonne Université, GRC n²0, Groupe de Recherche Clinique sur la Lithiase Urinaire, Hôpital Tenon, \\ F-75020 Paris, France; audrey.uzan@aphp.fr (A.U.); p.chiron@laposte.net (P.C.); \\ frederic.panthier@aphp.fr (F.P.); mattieu.haddad@gmail.com (M.H.); olivier.traxer@aphp.fr (O.T.) \\ 2 Sorbonne Université, Service d'Urologie, AP-HP, Hôpital Tenon, F-75020 Paris, France \\ 3 PIMM, UMR 8006 CNRS-Arts et Métiers ParisTech, 151 bd de l'Hôpital, F-75013 Paris, France; \\ laurent.berthe@ensam.eu \\ * Correspondence: steeve.doizi@aphp.fr; Tel.: +33-1-56-01-61-53; Fax: +33-1-56-01-63-77
}

check for updates

Citation: Uzan, A.; Chiron, P.; Panthier, F.; Haddad, M.; Berthe, L.; Traxer, O.; Doizi, S. Comparison of Holmium:YAG and Thulium Fiber Lasers on the Risk of Laser Fiber Fracture. J. Clin. Med. 2021, 10, 2960. https://doi.org/10.3390/jcm10132960

Academic Editor: Bhaskar K. Somani

Received: 10 May 2021

Accepted: 25 June 2021

Published: 30 June 2021

Publisher's Note: MDPI stays neutral with regard to jurisdictional claims in published maps and institutional affiliations.

Copyright: (c) 2021 by the authors. Licensee MDPI, Basel, Switzerland. This article is an open access article distributed under the terms and conditions of the Creative Commons Attribution (CC BY) license (https:// creativecommons.org/licenses/by/ $4.0 /)$.

\begin{abstract}
Objectives: To compare the risk of laser fiber fracture between Ho:YAG laser and Thulium Fiber Laser (TFL) with different laser fiber diameters, laser settings, and fiber bending radii. METHODS: Lengths of 200, 272, and $365 \mu \mathrm{m}$ single use fibers were used with a $30 \mathrm{~W}$ Ho:YAG laser and a $50 \mathrm{~W}$ Super Pulsed TFL. Laser fibers of $150 \mu \mathrm{m}$ length were also tested with the TFL only. Five different increasingly smaller bend radii were tested: $1,0.9,0.75,0.6$, and $0.45 \mathrm{~cm}$. A total of 13 different laser settings were tested for the Ho:YAG laser: six fragmentation settings with a short pulse duration, and seven dusting settings with a long pulse duration. A total of 33 different laser settings were tested for the TFL. Three laser settings were common two both lasers: $0.5 \mathrm{~J} \times 12 \mathrm{~Hz}, 0.8 \mathrm{~J} \times 8 \mathrm{~Hz}, 2 \mathrm{~J} \times 3 \mathrm{~Hz}$. The laser was activated for $5 \mathrm{~min}$ or until fiber fracture. Each measurement was performed ten times. Results: While fiber failures occurred with all fiber diameters with Ho:YAG laser, none were reported with TFL. Identified risk factors of fiber fracture with the Ho:YAG laser were short pulse and high energy for the $365 \mu \mathrm{m}$ fibers $(p=0.041)$, but not for the 200 and $272 \mu \mathrm{m}$ fibers $(p=1$ and $p=0.43$, respectively). High frequency was not a risk factor of fiber fracture. Fiber diameter also seemed to be a risk factor of fracture. The $200 \mu \mathrm{m}$ fibers broke more frequently than the 272 and $365 \mu \mathrm{m}$ ones $(p=0.039)$. There was a trend for a higher number of fractures with the $365 \mu \mathrm{m}$ fibers compared to the $272 \mu \mathrm{m}$ ones, these occurring at a larger bend radius, but this difference was not significant. Conclusion: TFL appears to be a safer laser regarding the risk of fiber fracture than Ho:YAG when used with fibers in a deflected position.
\end{abstract}

Keywords: Ho:YAG laser; thulium fiber laser; laser fiber; lithotripsy; urolithiasis; ureteroscopy

\section{Introduction}

Since its introduction in the 1990s, Ho:YAG laser has become the reference point for lasers for lithotripsy in urology because of its property to fragment all stone compositions, efficiencies and safety profiles [1-3]. Recently, a new laser has been released: the Super Pulsed Thulium Fiber Laser (TFL), with potential advantages over Ho:YAG laser such as higher ablation volumes during lithotripsy and production of thinner particles [4-8]. These two lasers use low hydroxyl silica optical fibers to transmit the laser beam to the stone $[4,5,9,10]$. During laser lithotripsy with flexible ureteroscopy (f-URS), laser fiber rupture may occur especially for lower pole stones treatment, resulting in working channel perforation and subsequent endoscope repair. Some studies reported risk factors of laser fiber fracture with Ho:YAG laser while bending: the diameter of the bend and high pulse energy [11,12]. While Ho:YAG laser and TFL are currently used for lithotripsy during $\mathrm{f}$-URS, there is a lack of comparative study regarding the risk of laser fiber fracture during laser activation in a deflected position. Thus, we aimed to compare the risk of laser fiber 
fracture between Ho:YAG laser and TFL with different laser fiber diameters, laser settings, and fiber bending radii.

\section{Materials and Methods}

\subsection{Laser Fibers}

Single use laser fibers of a unique manufacturer (Rocamed, Monaco) with core diameters of 200, 272, and $365 \mu \mathrm{m}$ were used for both laser systems to avoid any confusion due to a variability in laser fibers characteristics. Additionally, $150 \mu \mathrm{m}$ laser fibers were also tested with the TFL only.

\subsection{Laser Systems}

A 50 W Super Pulsed TFL generator (IPG Photonics, Fryazino, Russia) with a wavelength of $1940 \mathrm{~nm}$ was compared to a 30 W Ho:YAG laser (MH01-ROCA FTS-30W, Rocamed, Monaco) with a wavelength of $2120 \mathrm{~nm}$. A total of 13 different laser settings were tested for the Ho:YAG laser: 6 fragmentation settings with a short pulse duration, and 7 dusting settings with a long pulse duration. A total of 33 different laser settings were tested for the TFL. Since TFL offers lower energies and higher frequencies than current Ho:YAG lasers, we aimed to evaluate these specificities. Three laser settings were common to both lasers: $0.5 \mathrm{~J} \times 12 \mathrm{~Hz}, 0.8 \mathrm{~J} \times 8 \mathrm{~Hz}, 2 \mathrm{~J} \times 3 \mathrm{~Hz}$. All laser settings tested are presented in Table 1.

Table 1. (A): TFL laser settings; (B): Ho:YAG laser settings.

\begin{tabular}{|c|c|c|c|}
\hline \multicolumn{4}{|c|}{ A. TFL Settings } \\
\hline & $6 \mathrm{~W}$ & $25 \mathrm{~W}$ & $50 \mathrm{~W}$ \\
\hline \multicolumn{4}{|c|}{ Fine dusting (peak power $=125 \mathrm{~W})$} \\
\hline $0.025 \mathrm{~J}$ & $240 \mathrm{~Hz}$ & $1000 \mathrm{~Hz}$ & $2000 \mathrm{~Hz}$ \\
\hline $0.05 \mathrm{~J}$ & $120 \mathrm{~Hz}$ & $500 \mathrm{~Hz}$ & $1000 \mathrm{~Hz}$ \\
\hline $0.1 \mathrm{~J}$ & $60 \mathrm{~Hz}$ & $250 \mathrm{~Hz}$ & $500 \mathrm{~Hz}$ \\
\hline $0.15 \mathrm{~J}$ & $40 \mathrm{~Hz}$ & $167 \mathrm{~Hz}$ & $333 \mathrm{~Hz}$ \\
\hline \multicolumn{4}{|c|}{ Dusting (peak power = $125 \mathrm{~W}$ ) } \\
\hline $0.2 \mathrm{~J}$ & $30 \mathrm{~Hz}$ & $125 \mathrm{~Hz}$ & $250 \mathrm{~Hz}$ \\
\hline $0.5 \mathrm{~J}$ & $12 \mathrm{~Hz}$ & $50 \mathrm{~Hz}$ & $100 \mathrm{~Hz}$ \\
\hline $0.8 \mathrm{~J}$ & $7.5 \mathrm{~Hz}$ & $31.3 \mathrm{~Hz}$ & $62.5 \mathrm{~Hz}$ \\
\hline \multicolumn{4}{|c|}{ Fragmentation $($ peak power $=500 \mathrm{~W})$} \\
\hline $1 \mathrm{~J}$ & $6 \mathrm{~Hz}$ & $25 \mathrm{~Hz}$ & $50 \mathrm{~Hz}$ \\
\hline $2 \mathrm{~J}$ & $3 \mathrm{~Hz}$ & $12.5 \mathrm{~Hz}$ & $25 \mathrm{~Hz}$ \\
\hline $4 \mathrm{~J}$ & $1.5 \mathrm{~Hz}$ & $6.3 \mathrm{~Hz}$ & $12.5 \mathrm{~Hz}$ \\
\hline $6 \mathrm{~J}$ & $1 \mathrm{~Hz}$ & $4.2 \mathrm{~Hz}$ & $8.3 \mathrm{~Hz}$ \\
\hline \multicolumn{4}{|c|}{ B. Ho:YAG Laser Settings } \\
\hline \multicolumn{4}{|c|}{ Dusting (long pulse) } \\
\hline $0.2 \mathrm{~J}$ & $25 \mathrm{~Hz}$ & & \\
\hline $0.5 \mathrm{~J}$ & $3 \mathrm{~Hz}$ & $12 \mathrm{~Hz}$ & $15 \mathrm{~Hz}$ \\
\hline $0.8 \mathrm{~J}$ & $3 \mathrm{~Hz}$ & $8 \mathrm{~Hz}$ & $15 \mathrm{~Hz}$ \\
\hline \multicolumn{4}{|c|}{ Fragmentation (short pulse) } \\
\hline $1 \mathrm{~J}$ & $3 \mathrm{~Hz}$ & $5 \mathrm{~Hz}$ & $15 \mathrm{~Hz}$ \\
\hline $2 \mathrm{~J}$ & $3 \mathrm{~Hz}$ & $8 \mathrm{~Hz}$ & $12 \mathrm{~Hz}$ \\
\hline
\end{tabular}




\subsection{Experimental Setup}

The laser fibers were supported by soft silicone tubes, secured by plastic screws (to hold the fibers without causing damage). Failure threshold testing was done by bending fibers to $180^{\circ}$ with an initial radius of $1 \mathrm{~cm}$, Figure $1 \mathrm{~A}, \mathrm{~B}$. In total, five different increasingly smaller bend radii were tested: $1,0.9,0.75,0.6$, and $0.45 \mathrm{~cm}$. The choice of the minimal bending radius $(0.45 \mathrm{~cm})$ was based on the fact that we measured the most acute angle over several cases that a flexible ureteroscope might deflect for lower pole lithotripsy in difficult anatomical situations. Subsequent radii were randomly chosen to test wider values mimicking calices easier to navigate through. The laser was activated continuously for 5 min or until fiber fracture. Each measurement was performed ten times.

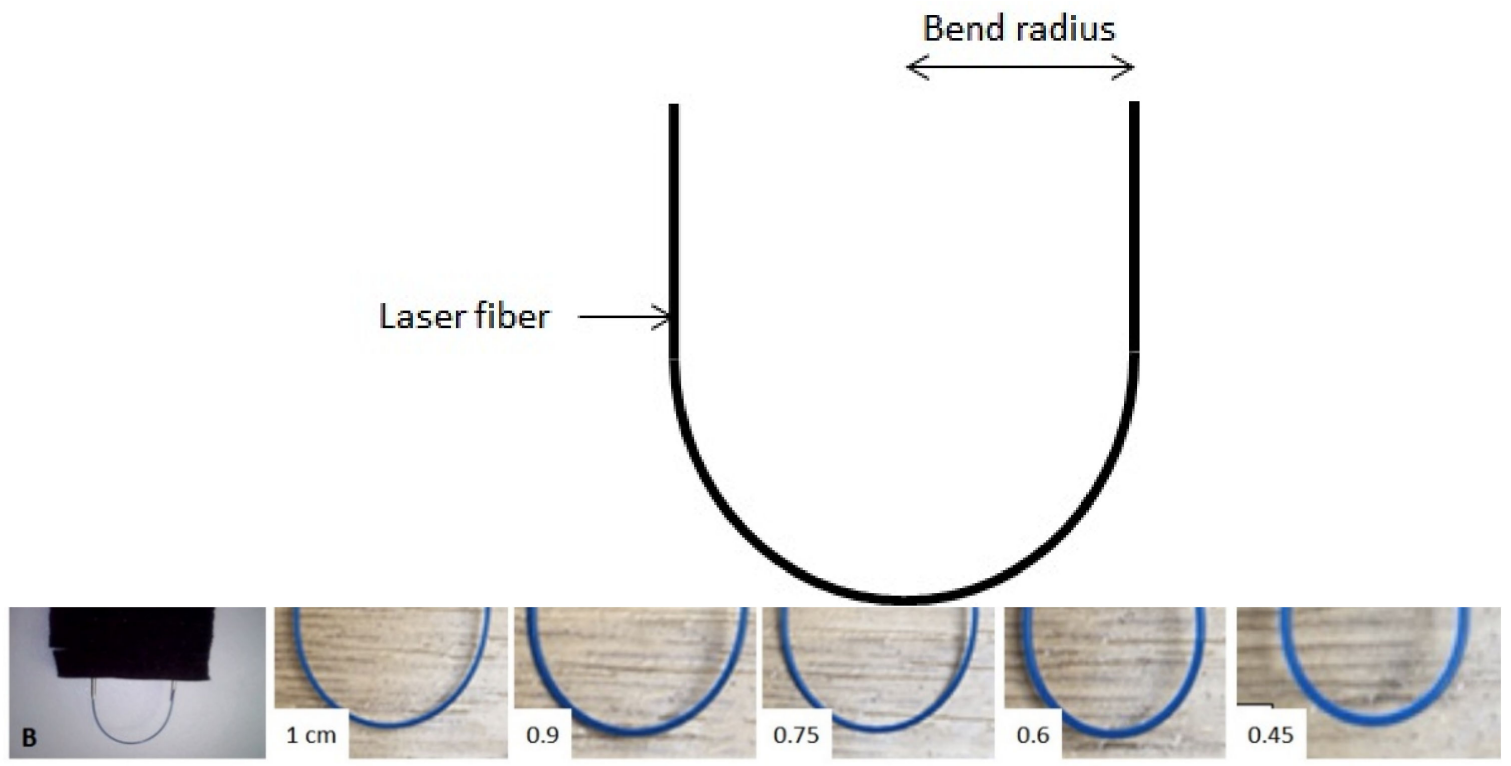

(A)

Figure 1. (A) Fiber bending radius, (B) Fiber bending radii tested.

\subsection{Statistical Analyses}

The Mann-Whitney test was used for comparisons between groups. All tests were conducted using the R Software, version 4.0.3. A $p$-value of 0.05 or less was considered significant.

\section{Results}

We did not report mechanical failure by bending the fibers alone. All fractures occurred after laser energy application.

\subsection{Ho:YAG Laser}

\subsubsection{Dusting Settings}

For the $200 \mu \mathrm{m}$ fibers, the fracture rate was $50 \%$ at bending radius $\leq 0.6 \mathrm{~cm}$, while none broke at radius $\geq 0.75 \mathrm{~cm}$. For the 272 and $365 \mu \mathrm{m}$ fiber diameters, fractures occurred only with a bending radius of $0.45 \mathrm{~cm}$. A total of $20 \%$ of the $272 \mu \mathrm{m}$ and $30 \%$ of the $365 \mu \mathrm{m}$ fibers broke at a bend radius of $0.45 \mathrm{~cm}$, Figure 2 . 


\section{Dusting setting}

$200 \mu \mathrm{m}$ laser fiber

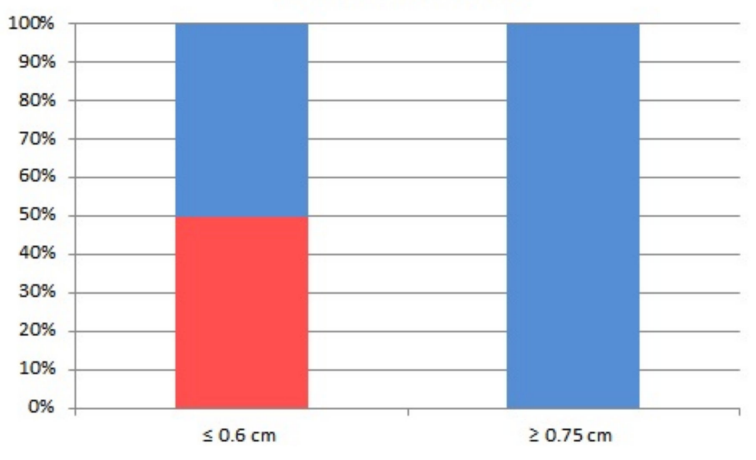

$272 \mu$ m laser fiber

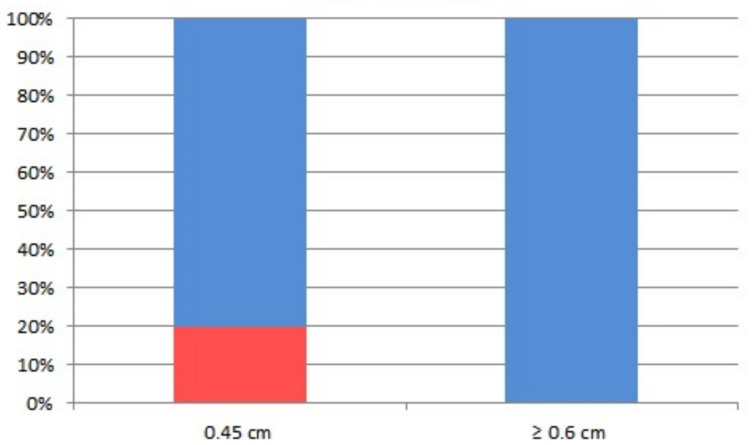

$365 \mu$ m laser fiber

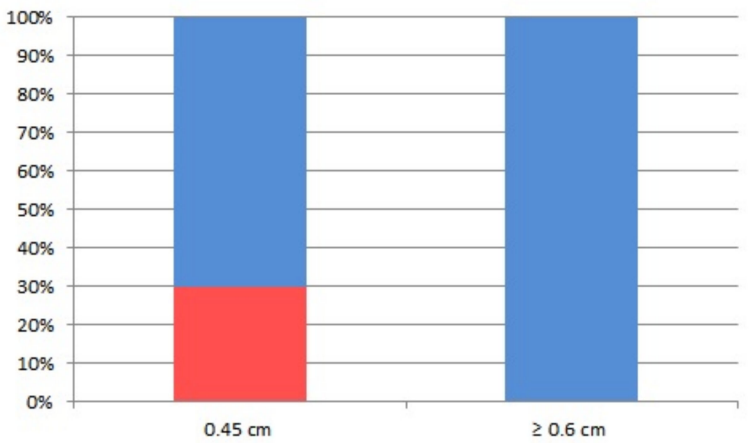

Fragmentation setting

$200 \mu \mathrm{m}$ laser fiber

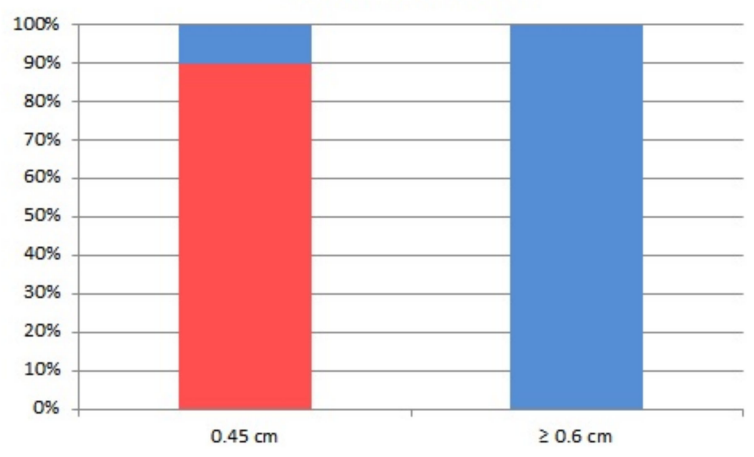

$272 \mu$ m laser fiber

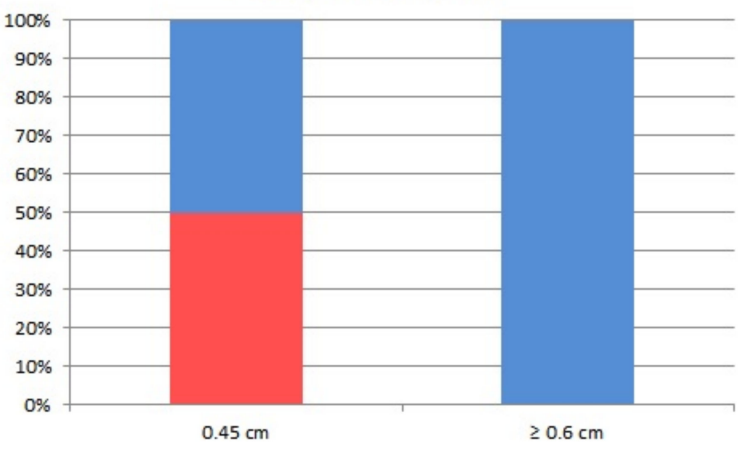

$365 \mu$ m laser fiber

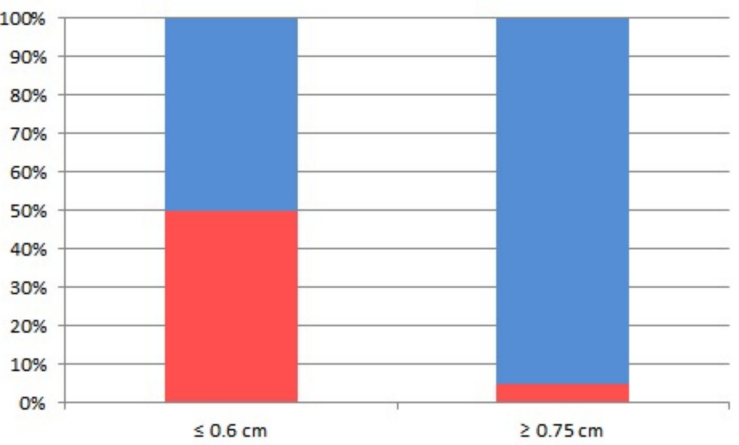

Laser fiber fracture

No laser fiber fracture

Figure 2. Proportion of fiber failures with Ho:YAG laser according to laser setting, fiber diameter, bending radius.

\subsubsection{Fragmentation Settings}

Of the 200 and $272 \mu \mathrm{m}$ fibers, there was no fracture for a bend radius $\geq 0.6 \mathrm{~cm}$. While $90 \%$ of the $200 \mu \mathrm{m}$ fibers broke at a radius of $0.45 \mathrm{~cm}, 50 \%$ of the $272 \mu \mathrm{m}$ did. The $365 \mu \mathrm{m}$ fibers broke more frequently at $\leq 0.75 \mathrm{~cm}$. A total of $5 \%$ and $50 \%$ of $365 \mu \mathrm{m}$ laser fibers broke with a bending radius of $\geq 0.75$ and $\leq 0.6 \mathrm{~cm}$, respectively, Figure 2 .

\subsubsection{Identification of Risk Factors of Fiber Failure}

Short pulse and high energy were significant risk factors of fiber fracture for the $365 \mu \mathrm{m}$ fibers ( $p=0.041$ ), but not for the 200 and $272 \mu \mathrm{m}$ fibers ( $p=1$ and $p=0.43$, respectively). High frequency was not a risk factor of fiber fracture for all fiber core diameters. 
Fiber diameter also seemed to be a risk factor of fracture. The $200 \mu \mathrm{m}$ fibers broke more frequently than the 272 and $365 \mu \mathrm{m}$ ones $(p=0.039)$. There was a trend for a higher number of fractures with the $365 \mu \mathrm{m}$ fibers compared to the $272 \mu \mathrm{m}$ ones, these occurring at a larger bend radius, but this difference was not significant.

\subsection{TFL}

Irrespective of the laser fiber diameter, laser settings, and bending radius, no fiber fracture occurred with the TFL.

\subsection{Ho:YAG versus TFL}

Irrespective of the laser settings, the fiber diameter and the bend radius, there was a significant risk of fiber fracture with the Ho:YAG laser compared to the TFL.

\section{Discussion}

The current study demonstrated a significant risk of fiber fracture with the Ho:YAG laser compared to the TFL in a deflected position. This result is of importance because nowadays f-URS has become a modality of choice for the treatment of kidney stones [13]. While Ho:YAG laser is currently the gold standard for lithotripsy during f-URS, TFL appears as an efficient alternative [14]. For both lasers, the laser energy is delivered to the target through a low hydroxyl silica fiber [9]. This laser fiber consists of a silica core through which the laser energy is transmitted. This core is surrounded by a layer called cladding that is essential for the efficient delivery of laser energy. This cladding is made of similar material to the core but has a different refractive index. Thus, the laser beam is reflected at the cladding-core interface. This process is called total internal reflection $[9,10]$. The most external part of the fiber is called jacket and encases the core and cladding. Its function is to protect the glass components of the fiber. When the fiber is bent, such as in lower pole stone treatment during f-URS, a small amount energy may leave the core to the cladding, and subsequently leak into the jacket. This condition represents a loss of total internal reflection of the laser energy, and once energy leaks into the jacket, fiber failure can occur due to thermal breakdown [15-17]. Prior studies demonstrated that the fibers do not fail with mechanical stress alone but rather fail when the laser is activated with the fiber in a deflected position. Consequences of such fiber failures are working channel perforations during laser activation, which represents an important cause of f-URS damage [18]. Several studies focused on the risk factors of fiber fracture in a deflected position with Ho:YAG laser [11,12,19-23]. They reported contradictory results regarding the influence of fiber diameter, bend radius, laser settings, and even for a same type of fiber from a specific manufacturer [12,20-22]. For example, while some authors reported that medium core fibers were prone to higher rates of failure than small core fibers, other studies did not document a correlation between increasing fiber diameter and fracture [11,20]. However, all the studies found that the resistance to fracture varies greatly among fiber manufacturers [12,20-22].

Similarly to Mues et al., we did not report mechanical failure by bending the fibers alone [21]. This means that failure is the consequence of loss of total internal reflection during laser activation in a bent fiber.

\subsection{Ho:YAG Laser}

The current study found that small core fibers $(200 \mu \mathrm{m})$ were prone to a higher rate of fracture and failed at a larger bend radius $(\leq 0.6 \mathrm{~cm})$ than 272 and $365 \mu \mathrm{m}$ fibers in dusting setting (0.45 cm only). Surprisingly, no $200 \mu \mathrm{m}$ fiber failure occurred at a bend radius $\geq 0.6 \mathrm{~cm}$ in fragmentation setting, but there was a higher proportion of fractures than in dusting setting ( $90 \%$ versus $50 \%$, respectively). Thus, we found that small core fibers failed significantly more often than the 272 and $365 \mu \mathrm{m}$ ones. These results are consistent with the report by Mues et al., and may be explained by the beam profile of the Ho:YAG laser [21]. Indeed, the Ho:YAG laser beam does not couple small core fibers 
$(<200 \mu \mathrm{m})$, and the risk may be overfilling the fiber core and leak laser energy to the fiber cladding, which can damage the fiber $[4,5,24,25]$. Thus, the use of small core fibers require the funneling of laser beam. As consequence, Ho:YAG laser is typically limited to larger fiber diameters $(270-500 \mu \mathrm{m})$.

For the 272 and $365 \mu \mathrm{m}$ fibers, we found similar results than Haddad et al., the $272 \mu \mathrm{m}$ fibers failed at a smaller diameter than the $365 \mu \mathrm{m}$ in fragmentation setting, but not in dusting setting.

Although $200 \mu \mathrm{m}$ fibers are more flexible and may be more suitable for the treatment of lower pole stones during f-URS, they are more prone to failure when lasering. Thus, $272 \mu \mathrm{m}$ core fibers seem a safer option for lower pole f-URS with Ho:YAG laser.

Finally, similarly to Knudsen et al., we found that the tightness of the fiber bend radius increases the risk of fiber failure as well as pulse energy for the $365 \mu \mathrm{m}$ only [12]. This means that for a fixed bending radius, if the pulse energy increases, the amount of energy leaking the core to the cladding increases, and thus the risk of fiber fracture. On the contrary, Lusch et al. reported a trend for less fiber fracture at long pulse mode, high energy, low frequency in the small core fibers $(200,272 / 273 \mu \mathrm{m})$. Contrary to Vassar et al., we did not report an increase failure rate when the laser pulse energy increases with $272 \mu \mathrm{m}$ fibers compared to the $365 \mu \mathrm{m}$ [26].

\subsection{TFL}

Until now, no study has evaluated the risk of laser fiber fracture with the TFL. We found that, irrespective of the laser fiber diameter, laser settings, and bending radius, no fiber fracture occurred. These results may be explained by the beam profile and the peak power of the TFL. Contrary to the solid state Ho:YAG laser, the laser beam of the TFL originates within a small $(18-25 \mu \mathrm{m})$ core of the thulium-doped silica optical fiber, which is about 100 times smaller in diameter than Ho:YAG laser. Furthermore, the TFL provides a near single mode Gaussian spatial beam profile, more uniform and symmetrical than the multimodal beam produced by the Ho:YAG laser [24]. Thus, even thinner laser fibers $(150 \mu \mathrm{m})$ can be used with TFL. As consequence, total internal reflection may be respected in all fiber core diameters, with no leakage of energy through the cladding and jacket, which reduce the risk of fiber fracture. Moreover, peak power may also explain the absence of fracture with TFL. Indeed, the differences in fiber fracture rates between the two lasers systems may be explained by the constant higher peak power with the Ho:YAG laser compared to the TFL, regardless of the laser settings [27]. While peak power is directly correlated to the energy level with Ho:YAG laser and decreases with increased pulse duration, this remains constant with TFL. Furthermore, the pulse shape is also different with a flat and uniform shape for the TFL and a spike with an overshoot for the Ho:YAG laser [27]. Thus, the treatment of lower pole stone with TFL may be safer than with Ho:YAG laser, regardless of fiber diameter, bend radius, and laser settings.

Our study has several limitations, including the use of laser fibers from a unique manufacturer. However, by using exactly the same laser fiber manufacturer, it was possible to show the differences between both laser technologies, without risking the additional bias that using laser fibers from different origins might introduce. Yet, since great differences regarding size, flexibility, and resistance to fracture with bending among manufacturers exist, more optical fibers should be tested to ascertain our results with TFL. Although, laser fiber manufacturers provide short term minimum bending radius, we did not respect them in our tests since it is not possible to respect these minimal values in real conditions, especially in a difficult lower calyx access. Indeed, short term minimum bending radii were $\geq 13 \mathrm{~mm}, \geq 17 \mathrm{~mm}$, and $\geq 21 \mathrm{~mm}$ for the 200,272 , and $365 \mu \mathrm{m}$ laser fibers tested, respectively. Another limitation was the absence of power transmission measurement. With transmission values, a quantitative correlation of core diameter, bending radius and losses might be possible. Lastly, laser activation duration was fixed at $5 \mathrm{~min}$ or until fiber fracture, which has resulted in different total energies delivered between powers tested. 
However, this might affect the results with Ho:YAG laser only, since no fiber fracture occurred with TFL.

\section{Conclusions}

The is the first study comparing the risk of fiber fracture with different laser fiber diameters, laser settings, and fiber bending radii between the Ho:YAG laser and TFL. While fiber failures occurred with all fiber diameters with Ho:YAG laser, none was reported with TFL. Further studies testing fibers from different manufacturers are needed to ascertain these results.

Author Contributions: Conceptualization, S.D.; data curation, S.D. and O.T.; formal analysis, S.D., P.C. and F.P.; investigation, S.D., P.C. and F.P.; methodology, S.D and F.P.; project administration, S.D.; resources, S.D.; validation, S.D.; writing—original draft, A.U.; S.D.; writing—review and editing, A.U., S.D., P.C. and F.P., M.H., L.B. and O.T. All authors have read and agreed to the published version of the manuscript.

Funding: This research received no external funding.

Institutional Review Board Statement: Not applicable.

Informed Consent Statement: Not applicable.

Data Availability Statement: Data are available by contacting authors.

Conflicts of Interest: Olivier Traxer is a consultant for: Boston Scientific, Coloplast, EMS, IPG Medical, Olympus, Rocamed. Audrey Uzan, Paul Chiron, Frédéric Panthier, Mattieu Haddad, Laurent Berthe, and Steeve Doizi have no conflict of interest to declare.

\section{References}

1. Johnson, D.E.; Cromeens, D.M.; Price, R.E. Use of the holmium:YAG laser in urology. Lasers Surg. Med. 1992, 12, $353-363$. [CrossRef]

2. Herrmann, T.R.; Liatsikos, E.N.; Nagele, U.; Traxer, O.; Merseburger, A.S. EAU Guidelines on Laser Technologies. Eur. Urol. 2012, 61, 783-795. [CrossRef]

3. Sayer, J.; Johnson, D.E.; Price, R.E.; Cromeens, D.M. Endoscopic laser fragmentation of ureteral calculi using the holmium:YAG. Proc. SPIE 1993, 1879, 143-148. [CrossRef]

4. Fried, N.M. Recent advances in infrared laser lithotripsy [Invited]. Biomed. Opt. Express 2018, 9, 4552-4568. [CrossRef] [PubMed]

5. Fried, N.M.; Irby, P.B. Advances in laser technology and fibre-optic delivery systems in lithotripsy. Nat. Rev. Urol. 2018, 15, 563-573. [CrossRef] [PubMed]

6. Keller, E.X.; De Coninck, V.; Doizi, S.; Daudon, M.; Traxer, O. Thulium fiber laser: Ready to dust all urinary stone composition types? World J. Urol. 2021, 39, 1693-1698. [CrossRef]

7. Panthier, F.; Doizi, S.; Lapouge, P.; Chaussain, C.; Kogane, N.; Berthe, L.; Traxer, O. Comparison of the ablation rates, fissures and fragments produced with 150 microm and 272 microm laser fibers with superpulsed thulium fiber laser: An in vitro study. World J. Urol. 2021, 39, 1683-1691. [CrossRef] [PubMed]

8. Traxer, O.; Keller, E.X. Thulium fiber laser: The new player for kidney stone treatment? A comparison with Holmium:YAG laser. World J. Urol. 2020, 38, 1883-1894. [CrossRef] [PubMed]

9. Nazif, O.A.; Teichman, J.M.; Glickman, R.D.; Welch, A.J. Review of Laser Fibers: A Practical Guide for Urologists. J. Endourol. 2004, 18, 818-829. [CrossRef]

10. Knudsen, B.E. Laser Fibers for Holmium:YAG Lithotripsy: What Is Important and What Is New. Urol. Clin. N. Am. 2019, 46, 185-191. [CrossRef]

11. Haddad, M.; Emiliani, E.; Rouchausse, Y.; Coste, F.; Doizi, S.; Berthe, L.; Butticé, S.; Somani, B.K.; Traxer, O. Impact of the Curve Diameter and Laser Settings on Laser Fiber Fracture. J. Endourol. 2017, 31, 918-921. [CrossRef] [PubMed]

12. Knudsen, B.E.; Glickman, R.D.; Stallman, K.J.; Maswadi, S.; Chew, B.H.; Beiko, D.T.; Denstedt, J.D.; Teichman, J.M. Performance and Safety of Holmium:YAG Laser Optical Fibers. J. Endourol. 2005, 19, 1092-1097. [CrossRef] [PubMed]

13. Türk, C.; Knoll, T.; Petrik, A.; Sarica, K.; Skolarikos, A.; Straub, M.; Seitz, C. EAU Guidelines on Urolithiasis. Eur. Urol. 2021. Available online: https:/ / uroweb.org/guideline/urolithiasis/ (accessed on 10 May 2021).

14. Enikeev, D.; Traxer, O.; Taratkin, M.; Okhunov, Z.; Shariat, S. A review of thulium-fiber laser in stone lithotripsy and soft tissue surgery. Curr. Opin. Urol. 2020, 30, 853-860. [CrossRef] [PubMed]

15. Lee, H.; Ryan, R.T.; Teichman, J.M.; Landman, J.; Clayman, R.V.; Milner, T.E.; Welch, A.J. Effect of lithotripsy on holmium:YAG optical beam profile. J. Endourol. 2003, 17, 63-67. [CrossRef]

16. Marks, A.J.; Teichman, J.M.H. Lasers in clinical urology: State of the art and new horizons. World J. Urol. 2007, 25, 227-233. [CrossRef] 
17. Heckscher, D.; Zeng, J.; Samolis, P.; Sander, M.Y.; Wason, S.E.L.; Wang, D.S. The Effect of Holmium Laser Fiber Bending Radius on Power Delivery During Flexible Ureteroscopy. J. Endourol. 2020, 34, 682-686. [CrossRef]

18. Afane, J.S.; Olweny, E.O.; Bercowsky, E.; Sundaram, C.P.; Dunn, M.D.; Shalhav, A.L.; McDougall, E.M.; Clayman, R.V. Flexible ureteroscopes: A single center evaluation of the durability and function of the new endoscopes smaller than 9Fr. J. Urol. 2000, 164, 1164-1168. [CrossRef]

19. Bourdoumis, A.; Christopoulos, P.; Raj, N.; Fedder, A.; Buchholz, N. A Comparative in Vitro Study of Power Output Deterioration over Time Between Ho:YAG Laser Fibers from Different Manufacturers as a Function of Deflection and Power Input. Curr. Urol. 2016, 9, 12-18. [CrossRef]

20. Akar, E.C.; Knudsen, B.E. Evaluation of 16 New Holmium: Yttrium-Aluminum-Garnet Laser Optical Fibers for Ureteroscopy. Urology 2015, 86, 230-235. [CrossRef] [PubMed]

21. Mues, A.C.; Teichman, J.M.; Knudsen, B.E. Evaluation of 24 Holmium:YAG Laser Optical Fibers for Flexible Ureteroscopy. J. Urol. 2009, 182, 348-354. [CrossRef] [PubMed]

22. Lusch, A.; Heidari, E.; Okhunov, Z.; Osann, K.; Landman, J. Evaluation of Contemporary Holmium Laser Fibers for Performance Characteristics. J. Endourol. 2016, 30, 567-573. [CrossRef]

23. Khemees, T.A.; Shore, D.M.; Antiporda, M.; Teichman, J.M.; Knudsen, B.E. Evaluation of a new 240-mum single-use holmium:YAG optical fiber for flexible ureteroscopy. J. Endourol. 2013, 27, 475-479. [CrossRef]

24. Griffin, S. Fiber optics for destroying kidney stones. Biophotonics Int. 2004, 11, 44-47.

25. Hutchens, T.C.; Gonzalez, D.A.; Irby, P.B.; Fried, N.M. Fiber optic muzzle brake tip for reducing fiber burnback and stone retropulsion during thulium fiber laser lithotripsy. J. Biomed. Opt. 2017, 22, 018001. [CrossRef]

26. Vassar, G.J.; Teichman, J.M.; Glickman, R.D. Holmium:YAG Lithotripsy Efficiency Varies with Energy Density. J. Urol. 1998, 160, 471-476. [CrossRef]

27. Ventimiglia, E.; Doizi, S.; Kovalenko, A.; Andreeva, V.; Traxer, O. Effect of temporal pulse shape on urinary stone phantom retropulsion rate and ablation efficiency using holmium:YAG and super-pulse thulium fibre lasers. BJU Int. 2020, 126, 159-167. [CrossRef] 